RESEARCH ARTICLE

\title{
A Study on Adoption Level of Mango Growers on the Recommended Technologies in Krishnagiri District of Tamil Nadu
}

\author{
Divya $\mathbf{G}^{* 1}$ and Arunachalam $\mathbf{R}^{1}$ \\ ${ }^{* 1}$ Department of Agricultural Extension and Rural Sociology, Tamil Nadu Agricultural University, Coimbatore-641 003
}

Received : $24^{\text {th }}$ February, 2020

Revised : $14^{\text {th }}$ March, 2020

Accepted : $24^{\text {th }}$ March, 2020

\begin{abstract}
Indian mango is a special product that substantiates the high standards of quality and bountiful of nutrients packed in it. Mango, affectionately called King of Fruits is the National fruit of India. Mango accounts for 40 per cent of the total fruit exports from the country. There is good scope for increasing the area and productivity of mango in the country. The present investigation was carried out in Krishnagiri district of Tamil Nadu with the primary objective of assessing the adoption level of the mango growers on the recommended technologies. Two blocks viz., Mathur and Uthangarai were purposively selected for the study, which have the maximum area under mango cultivation. Proportionate random sampling method was used to select 146 sample respondents from eight identified villages. Significant findings of the study revealed that cent per cent of respondents had adopted the recommended cultivation practices such as field preparation, season of planting, method of planting, conventional system of planting, manures, and fertilizers. Bangalora and Senthura were the prominent varieties adopted by them. Little more than ninety per cent of the respondents had adopted the practice of intercropping and few recommended plant protection technologies. Cent per cent of the respondents had not adopted the recommended post-harvest technologies.
\end{abstract}

Keywords: Mango growers, recommended technologies, adoption

\section{INTRODUCTION}

India's total horticulture production is estimated to rise marginally to 314.87 million tonnes in the 2018-19 crop year. The total horticulture production of the country is estimated to be at 314.87 million tonnes which is 1.01 per cent higher than horticulture production in 2017-18. Under the horticulture crops, the production of fruits is estimated to be around 97.38 million tonnes in 2018-19 compared to 97.36 million tonnes in the previous year (The Hindu, 2019). Amongst fruits, our country ranks first in the production of Bananas (25.7\%), Papayas (43.6\%) and Mangoes (including mangosteens and guavas) (40.4\%) (APEDA, 2019).

The Indian Mango is a special product that substantiates the high standards of quality and bountiful of nutrients packed in it. A single mango can provide up to 40 per cent of the daily dietary fibre needs. In India, India's share in the world mango market is about 15 per cent. Mango accounts for 40 per cent of the total fruit exports from the country. There is good scope for increasing the area and productivity of Mango in the country.The major mango-growing states are
Andhra Prad esh, Uttar Pradesh, Karnataka, Bihar, Gujarat, and Tamil Nadu. Krishnagiri is considered as prominent mango producing zone in Tamil Nadu and famed for its sweet and juicy mangoes. The district is also known as a hub for Mango pulp manufacturing in India and the local farmers with a small piece of land are flourishing because of the pulp Industries. Mango cultivated over an area 40,000 ha in this district. The average yield per ha has been estimated at around 10 tonnes if the climatic condition is favorable.

More than one crore trees got dried up in Krishnagiri district over the last four years affecting hundreds of farmers. The production of Mangoes, which used to be around ten lakh tonnes until a few years ago, has come down to a meager two lakh tonnes this season. This severe drop in production has in-turn, impacted pulp production.

Several literatures also confirmed that the farmers are experiencing a number of problems in their production and marketing aspects such as lack of knowledge about the application of Paclobutrazol, canopy management and use of improved mango harvester and lack of knowledge regarding pest 
and disease management (Desai et al., 2017) and also the majority of the commercial mango growers had acquired the skills which were simple and easy to practice but the acquisition of skills which were complex in nature was relatively low (Kadam et al., 2016).

Mango cultivators of India are facing grave challenges including; very small land holdings, nonavailability of quality seedlings/saplings, huge postharvest loss due to dearth of infrastructure, middle man menace, lack of support by the concerned nodal bodies, lack of cooperative effort,poor profitability of the cultivation activity, etc., leading to the negative growth rate (- 0.86\%) (Bung,2015)., The high cost of inputs such as high yielding variety seeds, herbicides, fertilizers, bio-fertilizers, and pesticides, was felt as a major constraint and hence, the farmers could not afford to buy these inputs. It has been considered as an important threat to the adoption of the coping mechanism (Suganthkumar, 2017).

Marketing problems faced by the mango growers were high fluctuation in the market price, thus at the end of the season, prices go too down, which is not at all profitable for farmers and also high wages of labors for working in the orchard (Thakur, 2017).

A thorough understanding of their existing pattern of adoption, reasons for non-adoption of the recommended technologies, would help in developing appropriate strategies to improve the present situation, and hence the study was undertaken with the specific objective to assess the adoption level of Mango growers on the recommended technologies.

\section{MATERIAL AND METHODS}

The study was conducted in Mathur and Uthangarai blocks of Krishnagiri district of Tamil Nadu. Based on statistical data of maximum mango cultivated areas in the district, these blocks were selected purposively. As compared to other villages, by considering the maximum area, the villages such as Kondireddipatti, Marappa nayakampatti, Salamarathupatti and Kannadahalli from Mathur block and the villages Oobagavalasai, Kethunaikenpatti, Thiruvanampatti and Moondrampatti from Uthangarai block were selected. Totally there were 1466 mango producing farmers in the selected villages. Proportionate random sampling method was adopted to select ten per cent of the total farmers as respondents for the study, and hence the sample size has been fixed as 146 respondents. Ex-post-facto research design was employed for conducting the study. Ex-post-facto research is a systematic empirical enquiry in which the scientist does not have direct control over independent variables because their manifestations have already occurred or because they are inherently not manipulatable. Inferences about relations among variables are made, without direct intervention, from a concomitant variation of independent and dependent variables (Kerlinger, 1973). Data were collected by using a well-structured and pre-tested interview schedule by employing personal interview method. The responses were scored, quantified, categorized and tabulated using statistical methods like cumulative frequency method and percentage analysis.

\section{RESULTS AND DISCUSSION}

The findings are discussed with regard to the item-wise adoption of the recommended practices by the farmers and also the overall level of adoption of the recommended practices.

\section{Item wise analysis of adoption of the recommended technologies by the respondents in Mango cultivation.}

The pattern of the adoption of the technologies are discussed into four categories such as crop production technologies, crop protection technologies, harvesting, and post-harvesting technologies.

\section{Crop production technologies}

Under the crop production technologies, there were 12 technologies identified, and on which the respondents' level of adoption was assessed.

The following are the 12 identified technologies regarding crop production

- Field preparation

- Varieties suitable for TamilNadu

- Planting season

- Planting materials used

- Planting method

- Irrigation

- Spacing recommended

- Intercropping

- Manures and fertilizers recommended

- Canopy management

- Top working of senile orchards for rejuvenation

- Use of Growth regulators to induce flowering and fruit set.

These are the recommended technologies of Tamil Nadu Agricultural University (TNAU), which acts as the guide for mango growers in order to attain maximum yield and profit. Hence the recommended technologies were selected from the TNAU Agritech

$107|1-3| 98$ 
Table 1. The findings pertinent to the item-wise adoption level of the respondents on the recommended technologies

$\left(n=146^{*}\right.$

\begin{tabular}{|c|c|c|c|c|c|}
\hline \multirow{2}{*}{\multicolumn{2}{|c|}{ TNAU Recommended Technologies }} & \multicolumn{2}{|c|}{ Adopted } & \multicolumn{2}{|c|}{ Not Adopted } \\
\hline & & No & $\%$ & No & $\%$ \\
\hline \multicolumn{6}{|l|}{ A.Crop production technologies } \\
\hline Field preparation & Pit size $1 \mathrm{~m} \times 1 \mathrm{~m} \times 1 \mathrm{~m}$ & 146 & 100.00 & & \\
\hline \multirow[t]{9}{*}{ Varieties suitable for Tamil Nadu } & Banganapalli & 53 & 36.30 & 93 & 63.70 \\
\hline & Bangalora & 146 & 100.00 & - & \\
\hline & Neelum & 123 & 84.20 & 23 & 15.80 \\
\hline & Rumani & 20 & 13.70 & 126 & 86.30 \\
\hline & Mulgoa & 78 & 54.90 & 64 & 45.10 \\
\hline & Alphonso & 110 & 75.90 & 35 & 24.10 \\
\hline & Senthura & 145 & 99.30 & 1 & 0.70 \\
\hline & Kalepad & 9 & 6.20 & 137 & 93.80 \\
\hline & Imam pasand & 29 & 19.90 & 117 & 80.10 \\
\hline Planting season & July to December & 146 & 100.00 & - & \\
\hline \multirow[t]{2}{*}{ Planting material used } & Approach grafts & 1 & 0.70 & 145 & 99.30 \\
\hline & Epicotyl grafts & 137 & 93.80 & 9 & 6.20 \\
\hline Planting method & $\begin{array}{l}\text { Grafts planted in centre followed by adequate watering and } \\
\text { supporting with staking }\end{array}$ & 146 & 100.00 & - & \\
\hline \multirow[t]{3}{*}{ Irrigation } & Regular watering till establishment & 146 & 100.00 & - & \\
\hline & Conventional irrigation system & 121 & 82.90 & 25 & 17.10 \\
\hline & Micro-irrigation system & 27 & 18.50 & 119 & 81.50 \\
\hline \multirow[t]{3}{*}{ Spacing recommended } & Conventional system of planting $(7-10 \mathrm{~m})$ & 146 & 100.00 & - & \\
\hline & High Density Planting $(5 \mathrm{~m} \times 5 \mathrm{~m})$ & - & - & 146 & 100.00 \\
\hline & Double hedge row system & - & - & 146 & 100.00 \\
\hline Intercropping & During pre-bearing stage & 134 & 91.80 & 12 & 8.20 \\
\hline \multirow[t]{3}{*}{ Manures and fertilizers recommended } & FYM- $10 \mathrm{Kg}, \mathrm{N}-0.20 \mathrm{Kg}, \mathrm{P}-0.20 \mathrm{Kg}, \mathrm{K}-0.30 \mathrm{Kg}$ (per tree) & 146 & 100.00 & - & \\
\hline & Manures and Fertilizers applied during sep-oct & 146 & 100.00 & - & \\
\hline & Fertilizer application at 45 to $90 \mathrm{~cm}$ away from trunk. & 146 & 100.00 & - & \\
\hline \multirow[t]{4}{*}{ Canopy management } & Judicious pruning of internal branches (once in three years) & 146 & 100.00 & - & \\
\hline & Not allow flowering upto three years & 46 & 100.00 & & \\
\hline & Retaining two terminal healthy shoots annually during Aug-sep & 38 & 26.00 & 108 & 74.00 \\
\hline & Pruning $20 \mathrm{~cm}$ of terminals immediately after harvest & 108 & 74.0 & 38 & 26.00 \\
\hline \multirow{2}{*}{$\begin{array}{l}\text { Top working of senile orchards for } \\
\text { rejuvenation. }\end{array}$} & Use scions of Alphonso and Banganapalli for top working. & - & - & 146 & 100.00 \\
\hline & $\begin{array}{l}\text { Adopt cleft or softwood grafting on emerging shoots of main } \\
\text { stem }\end{array}$ & - & - & 146 & 100.00 \\
\hline \multirow{4}{*}{$\begin{array}{l}\text { Use of Growth regulators to induce } \\
\text { flowering and fruit set. }\end{array}$} & NAA@ 20 ppm & 146 & 100.00 & - & \\
\hline & $0.5 \%$ Urea ( $5 \mathrm{~g} /$ lit.) or $1 \%$ Potassium Nitrate ( $10 \mathrm{~g} /$ lit.) & 104 & 71.20 & 42 & 28.80 \\
\hline & Spraying of $2 \% \mathrm{KNO} 3$ at mustard size. & 146 & 100.00 & - & \\
\hline & Paclobutrazol @ $10 \mathrm{~g}$ a.i. for non-bearing trees. & 13 & 8.90 & 133 & 91.10 \\
\hline \multicolumn{6}{|l|}{ B.Crop Protection technologies } \\
\hline \multicolumn{6}{|l|}{ Pests } \\
\hline \multirow[t]{3}{*}{ Hopper } & Acephate 75 SP@ 1g/lit & 136 & 93.20 & 10 & 6.80 \\
\hline & Phosphamidon + neem oil $5 \mathrm{ml} /$ lit of water & - & & 146 & 100.00 \\
\hline & Wettable sulphur @ 2 g/lit & 23 & 15.80 & 123 & 84.20 \\
\hline Leaf galls and Aphids & Dimethoate or Methyl demeton @ $2 \mathrm{ml} /$ lit & 120 & 82.20 & 26 & 17.80 \\
\hline Flower Webber & Phosalone 35 EC @ 2 ml/lit & 135 & 92.50 & 11 & 7.50 \\
\hline Stem borer & Carbofuran 3 G @ 5g per bore hole & 28 & 19.20 & 118 & 80.80 \\
\hline \multirow[t]{2}{*}{ Fruit fly } & Malathion $2 \mathrm{ml} /$ lit. & 8 & $5 . .50$ & 138 & 94.50 \\
\hline & $\begin{array}{l}\text { Pheromone trap with methyl eugenol } 1 \mathrm{ml} \text { in } 1 \text { litre of } \\
\text { water }+1 \mathrm{ml} \text { of malathion solution }\end{array}$ & 101 & 69.20 & 45 & 30.80 \\
\hline \multicolumn{6}{|c|}{ 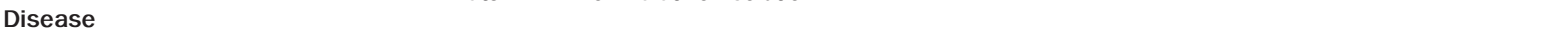 } \\
\hline Powdery mildew & Sulphur dust or Tridemorph $0.05 \%$. & 73 & 50.00 & 73 & 50.00 \\
\hline Anthracnose and stalk end-rot & Mancozeb $2 \mathrm{~g} /$ lit or Carbendazim $1 \mathrm{~g} /$ lit & 118 & 80.80 & 28 & 19.20 \\
\hline Mango malformation & 100-200 ppm NAA during October & 79 & 54.10 & 67 & 45.90 \\
\hline & $\begin{array}{l}\text { Pruning } 15-20 \mathrm{~cm} \text { diseased parts, followed by spraying of } \\
\text { Carbendazim (0.1\%). }\end{array}$ & - & & 146 & $100 . .00$ \\
\hline Stem end rot & Dip mangoes in 6 per cent borax solution at $43^{\circ} \mathrm{C}$ for 3 minut & & & 146 & 100.00 \\
\hline & Carbendazim $(0.1 \%)$ or Chlorothalonil $(0.2 \%)$ & 106 & 72.60 & 40 & 27.40 \\
\hline Red rust & Bordeaux mixture (1\%), or Copper oxychloride $0.25 \%$ & 137 & 93.80 & 9 & 6.20 \\
\hline C.Technologies on harvest & & & & & \\
\hline Harvesting time & March - June & 146 & 100.00 & - & \\
\hline D.Post-harvest treatment & $\begin{array}{l}\text { Dip fruits in } 52 \pm 1^{\circ} \mathrm{C} \text { hot water immediately after harvest for } \\
5 \text { minutes followed by } 8 \% \text { plant wax. }\end{array}$ & - & - & 146 & 100.00 \\
\hline & Two pre-harvest sprays of $0.20 \%$ Mancozeb ( $2.0 \mathrm{~g} / \mathrm{lit})$ & - & - & 146 & 100.00 \\
\hline
\end{tabular}

$107 \mid$ | 1-3 | 99 
portal thus, it paves the way for mango growers in search of various new technologies related to the crop, respectively.

The findings in the table revealed that cent per cent of the respondents have adopted the recommended pit size of $1 \mathrm{~m} \times 1 \mathrm{~m} \times 1 \mathrm{~m}$ for planting the crops. As regards the varieties, cent per cent of the respondents stated thus the varieties Banglora $(100.00 \%)$ and Senthura $(99.30 \%)$ were their most preferred varieties as these varieties are very much suitable to local climatic conditions. Moreover, these two varieties are most preferred by the local pulp industries considering their juice content. The varieties such as Neelum (84.20\%), Alphonso (75.90 \%), and Mulgoa (54.90\%) were in the next order of adoption by the respondents. Around little more than one-third of respondents (36.30 $\%$ ) have also cultivated the variety Banganapalli and around one-fifth of the respondents (19.90\%) have adopted Imam pasand. The varieties such as Rumani, Kalepad were also adopted by a lesser percentage of the respondents. Among the above varieties, Alphonso, Neelum, and Mulgoa were sold through local markets for direct consumption as they are the much-preferred varieties by the consumers for direct consumption purposes.

As regards the planting season, cent per cent of the respondents have adopted the recommended planting season of July to December. Here 93.80 per cent of the respondents have used epicotyl grafts for planting. These grafts were planted in the centre of the pit, followed by adequate watering and supported with staking by all the respondents.

Three different types of irrigation methods were followed in the study area viz., Regular watering till establishment, Conventional system of irrigation, and micro-irrigation system. Here all the respondents have regularly irrigated the crop till establishment (@2-3 irrigation per week). The conventional irrigation method was followed by most of the respondents (82.90\%), whereas 18.50 per cent of the respondents alone adopted the micro-irrigation method. Here, the initial higher investment of drip irrigation system, the low-quality drip materials and the frequent blockage inside the drippers were the main prominent reasons quoted by the respondents for the poor adoption of the micro-irrigation system as shown in the table.

There were three recommended spacing methods, such as the conventional system of planting $(7-10 \mathrm{~m})$, High-density planting $(5 \mathrm{~m} \times 5 \mathrm{~m})$, and Double hedge row system of planting in the study area. All the respondents have adopted only the conventional system of planting and none of the respondents have adopted the remaining two methods. Here, the farmers felt that the conventional system of planting is very much comfortable for them as it is being followed for a very long time in the study area besides providing remunerative yield. The farmers also felt that they had not perceived any significant difference among the three systems of planting. Hence, the conventional system of planting was much adopted by the respondents as it is ruling in the local area for a very long time.

Cultivation of intercrops was also recommended as one of the income-generating avenues for the mango farmers during the pre-bearing stage. Here, around 90.00 per cent of the respondents (91.80\%) have gone for raising intercrop. The crops like groundnut, horse gram, and tomato were their most prominent intercrops. Only a meagre percentage of respondents $(8.20 \%)$ have not cultivated any intercrops, which may be due to their ignorance, lack of interest, and poor market orientation.

Among the recommended manures and fertilizers, cent per cent of the respondents have applied the recommended dose of FYM $(10 \mathrm{~kg} /$ tree),Nitrogenous $(0.20 \mathrm{~kg} /$ tree), Phosphatic $(0.30$ $\mathrm{kg} /$ tree) and potassium (0.30 kg/tree) fertilizers. They have also applied the recommended dose of the above manures and fertilizers during the recommended period of September and October. It is also an appreciable fact all the respondents have meticulously adopted the practice of applying the recommended fertilizers at $45-90 \mathrm{~cm}$ away from the trunk.

As regards canopy management, cent per cent of respondents have judiciously pruned the internal branches once in 3 years, and also they have not allowed flowering upto 3 years. It is also recommended that during Aug-sep month, through appropriate pruning, two healthy terminal shoots to be retained in order to boost up the yield potential of the mango crop. Here, only around one-fourth of the respondents (26.00\%) alone have adopted this technology. Remaining respondents have not adopted for which they mentioned the laborious nature of the practice as the main reason. Pruning of $20 \mathrm{~cm}$ of terminals immediately after harvest is also a recommended practice under canopy management. It was meticulously adopted by about three fourth of the respondents (74.00\%). Remaining respondents have not adopted this technology, again considering the labor-intensive nature of technology.

As regards rejuvenation techniques, using scions of Alphonso and Banganapalli for top working is an important recommended technology. In the study area, none of the respondents have adopted this technology. Similarly, another recommended technology such as the cleft or softwood grafting on 
emerging shoots of the main stem was not adopted by the respondents. None of the respondents have adopted the above two technologies for which the respondents stated their lack of awareness and lack of understanding about the importance of the technologies and also the lack of skill on the technologies.

There were about four different methods recommended to induce flowering and fruit set. Cent per cent of the respondents have adopted NAA spray (@20 ppm) and $\mathrm{KNO}_{3}(2 \%)$ spray at the mustard size. Little more than seventy per cent of the respondents $(71.20 \%)$ have adopted the practice of spraying $0.5 \%$ urea or $1 \%$ potassium nitrate. Only a meagre percentage of respondents have adopted the recommended technology of paclobutrazol (@10g a.i.) for non-bearing trees.

\section{Crop protection technologies}

The results as given in the table1, revealed that little more than ninety percent of the respondents (93.20\%) have applied Acephate 75 SP(@1g/lit) followed by 15.80 per cent of the respondents applied wettable sulphur (@2g/lit) for the management of hoppers in mango. None of the respondents have used phosphamidon and neem oil combination for the management of the hopper. For the management of leaf galls and aphids, most of the respondents $(82.20 \%)$ have adopted the recommended technology. As regards, the flower webber management, around ninety per cent of the respondents (92.50\%) has adopted the recommended technology. Only around onefifth of the respondents (19.20\%) have adopted the recommended technology of carbofuran $3 G$ application for the management of stem borer. With regard to this fruit fly management, around seventy per cent of the respondents (69.20\%) have well adopted the recommended technology of pheromone trap with methyl eugenol and malathion combination. Only a very meagre percentage of the respondents have applied Malathion @2ml/lit. With

regards to the disease management, half of the respondents have well adopted the recommended technology of using sulphur dust or Tridemorph for the management of powdery mildew. For the management of Anthracnose and stalk end rot, the recommended technology of using Mancozeb and carbendazim was adopted by most $(80.80 \%)$ of the respondents. Mango malformation was managed by 54.10 per cent of the respondents by spraying NAA @ 100-200 ppm during October month. None of the respondents have adopted the recommended technology of pruning diseased parts, followed by spraying with carbendazim. For the management of stem end rot, around three fourth of the respondents (72.60\%) have adopted carbendazim or chlorothalonil in recommended doses. To manage stem end rot disease, there is another recommendation of dipping mangoes in six per cent borax solution at $43^{\circ} \mathrm{C}$ for 3 minutes, but it was not adopted by any of the respondents which they quoted their lack of awareness in this management technique as the main reason. For the management of Red rust, 93.80 per cent of the respondents have used Bordeaux mixture or Copper oxychloride in recommended doses.

\section{Adoption of technologies pertaining to harvest}

Cent per cent of the respondents have harvested their produce at the recommended harvesting time (March-june)

\section{Technologies on post-harvest}

There were two technologies recommended to preserve safely harvested mango, such as dipping fruits in $52 \pm 1^{\circ} \mathrm{C}$ hot water immediately after harvest for 5 minutes and two pre-harvest sprays with Mancozeb. Here, none of the respondents have adopted these two recommended technologies owing to their lack of awareness.

Overall level of adoption of the recommended technologies by the respondents in Mango cultivation. The relevant findings are available in Table 2.

Table 2.Overall level of adoption of recommended technologies by the respondents

$(n=146)$

\begin{tabular}{crrr}
\hline S.No & Category & Number & Per cent \\
\hline 1 & Low & 27 & 18.5 \\
2 & Medium & 102 & 69.9 \\
3 & High & 17 & 11.6 \\
\hline & Total & 146 & 100.0 \\
\hline
\end{tabular}

From the table 2, it could be observed that majority of the respondents (70.00\%) possessed a medium level of adoption of the recommended technologies, about one-fifth of the respondents (18.50 \%) had low adoption level whereas, a lesser proportion of respondents (11.60\%) had high adoption level. Any how it could be summarised that most of the respondents $(81.50 \%)$ were found distributed between medium to high level of adoption categories. 


\section{CONCLUSION}

It could be understood from the findings that the respondents are almost equally distributed among the 'adopted' and 'non-adopted' categories with regard to the recommended technologies.

The adoption of following technologies is very low among the mango growers

- Approach grafts.

- High-density planting.

- Double hedge row system of planting .

- Top working of senile orchards for rejuvenation.

- Use of paclobutrazol growth regulator for flowering and fruit set.

- Phosphomidon + neem oil $5 \mathrm{ml} /$ lit of water for the control of hopper

- Pruning 15-20 cm diseased parts, followed by spraying of carbendazim

- Dipping mangoes in six per cent borax solution at $43^{\circ} \mathrm{C}$ for 3 minutes for the control of stem end rot.

- Use of malathion $2 \mathrm{ml} / \mathrm{lit}$ for the control of fruit fly.

- Technologies pertaining to postharvest.

Poor adoption of the above-recommended technologies would lead to lower yield in mango, and consequently, it would affect their income level.

The local extension functionaries should design appropriate training methodologies to inculcate knowledge and skill on the above technologies. The respondents should be sensitized on the importance of the above technologies so as to realize the fullest yield potential from mango. Periodic skill demonstrations, diagnostic field visits, and the distribution of appropriate technical literature would help to solve the issue. The field extension scientists of local KVK could also be involved in bridging their adoption gap.
Though mango is a high remunerative export potential crop, the linkages of farmers with formal sources were low compared to informal sources like progressive farmers, fellow farmers, friends/ relatives. The department of horticulture should not limit its function to extent subsidies but ensure timely technical guidance especially for the small and medium mango growers. There is a need to proactively manage the two-way movements and coordination of goods, services, information, and funds to develop the potential in the domestic and international market.

\section{REFERENCES}

Retrieved from https://www.thehindubusinessline. com/economy/agri-business/horticulture production-marginally-up-at-31487-mt-in-2018-19/ article27379179.ece

Retrieved from http://apeda.gov.in/apedawebsite/ six head product/FFV.htm

Kerlinger, F.N. 1973. Foundation of Behavioral Research, Halt Rinehart and Winston Inc., New York. 379

Bung, Purushottam. 2015. "Challenges facing mango cultivators of India and the feasible solutions." International Journal of Management and Development Studies 4(3): 250-255.

Desai nagappa et al. (2017). Yield Gap Analysis in Adoption of Production Technology of Mango by the Farmers. Asian Journal of Agricultural Extension, Economics \& Sociology, 15(3): 1-12.

Thakur, Sayali V. and Bhange, S.B. (2017). Economic constraints faced by the mango growers. Agric. Update, 12(1): 133-136.

Kadam et al (2016). To Know the Skills of Commercial Mango Growers in the Use of Commercial Mango Production Technology. Advances in Life Sciences 5(17): 6969-6971.

Suganthkumar, P and Philip, H.(2017). A Study on the constraints Faced by the Rice Growers While Adopting the Climate Based Adaptation Strategy, Madras Agric. J., 104(10-12): 386-388. 